\title{
Investigating and characterizing the binding activity of the immobilized calmodulin to calmodulin-dependent protein kinase I binding domain with atomic force microscopy
}

\author{
Xiaoning Zhang ${ }^{1 *}$ and Hongmei $\mathrm{Hu}^{2}$
}

\begin{abstract}
Protein-protein interactions are responsible for many biological processes, and the study of how proteins undergo a conformational change induced by other proteins in the immobilized state can help us to understand a protein's function and behavior, empower the current knowledge on molecular etiology of disease, as well as the discovery of putative protein targets of therapeutic interest. In this study, a bottom-up approach was utilized to fabricate micro/ nanometer-scale protein patterns. One cysteine mutated calmodulin (CaM), as a model protein, was immobilized on thiol-terminated pattern surfaces. Atomic Force Microscopy (AFM) was then employed as a tool to investigate the interactions between CaM and CaM kinase I binding domain, and show that the immobilized CaM retains its activity to interact with its target protein. Our work demonstrate the potential of employing AFM to the research and assay works evolving surface-based protein-protein interactions biosensors, bioelectronics or drug screening.
\end{abstract}

Keywords: Protein-protein interactions, Calmodulin, CaM kinase I binding domain, Atomic force microscopy, Micro/nanometer-scale

\section{Introduction}

Protein patterning techniques in micro/nanometer-scale has demonstrated its huge potentials in bio-sensing and bio-analysis field [1-3]. The main advantages of these protein micro/nano-arrays technologies include high detection sensitivity, low consumptions of reagent samples (nL level), and a few protein requirements [4]. Typically, upon binding of ligand to the immobilized protein, there is a change in protein conformation. This ligandmediated conformation change can be devised to alter the scientific signal of biosensor, which can be analyzed by assessing any of its observable properties (e.g. optical or electrochemical properties).

Calcium, like many other inorganic elements, plays key roles in a variety of biological processes, such as

\footnotetext{
*Correspondence: XZhang@swu.edu.cn

${ }^{1}$ College of Biotechnology, Southwest University, Chongqing 400715, China

Full list of author information is available at the end of the article
}

the blood-clotting process, metabolism and signal transduction. Lots of $\mathrm{Ca}^{2+}$ dependent proteins exist in the cytoplasma of cells, calmodulin (CaM) is one of them, which is ubiquitous in almost all eukaryotic cells [5]. CaM is a small (148 amino acid residues), acidic (PI $=4.3$ ), and heat-stable protein, which can be exposed to temperatures higher than $90{ }^{\circ} \mathrm{C}$ and remains stable. Calcium-bound $\mathrm{CaM}\left(\mathrm{Ca}^{2+} / \mathrm{CaM}\right)$ can bind and activate a series of kinases in order to mediate the effects of $\mathrm{Ca}^{2+}[6-8]$. The multifunctional $\mathrm{Ca}^{2+} /$ CaM-dependent protein kinase I, also known as CaM kinase I (CaM KI) is a well-known effector of calciumand CaM-mediated functions. It is found in many tissues, but in neurons it has especially high concentrations, and it may be up to $2 \%$ of the total protein in some brain regions. Based on Dzhura's work, the CaM KI mediates phosphorylation and plays a fundamental part in triggering $I_{c a}$ facilitation, which responses to the intracellular $\mathrm{Ca}^{2+}$ concentration $[9,10]$. When an external stimulus increases intracellular $\mathrm{Ca}^{2+}$ levels, it 
increases the amount of $\mathrm{Ca}^{2+} / \mathrm{CaM} . \mathrm{Ca}^{2+} / \mathrm{CaM}$ then bind to the autoinhibitory domain of the $\mathrm{CaM} \mathrm{KI}$ $\alpha$-subunit and activate CaM KI by causing the binding domain to dissociate from the autoinhibitory domain. The activated CaM KI migrates to the post-synaptic density (PSD), phosphorylates $\alpha$-amino-3-hydroxy-5methyl-4-isoxazolepropionic acid receptors (AMPA receptors), which are ionotropic transmembrane receptors, and enhances their activity to decrease the $\mathrm{Ca}^{2+}$ level. Therefore, CaM activates CaM KI by displacement of its binding domain, and the capability of $\mathrm{CaM}$ to bind with CaM KI binding domain is able to indicate the activity of CaM to interact with CaM KI.

Protein-protein interactions, which are responsible for many biological processes [11, 12], have been extensively studied through a number of alternative ways, such as fluorescence technique [13, 14], electrophoresis [15, 16], microcalorimetry [17], et al. However, most of those techniques characterize protein-protein interaction in bulk solution. Only a small percentage of the published work done to reveal how proteins undergo a conformational change induced by protein-protein interaction in the immobilized state, and AFM is one of techniques used. Besides, AFM could help us to understand the architecture of a protein and a multiprotein complex in air directly. In addition, AFM is the only microscopic technique which is capable of visualizing biomolecules at the single-molecule level with sub-nanometer accuracy. Because AFM allows studying the adhesion, elasticity, association process, dynamics and other properties of biological sample, it is able to help us to quantitatively analyse protein-protein interactions to reveal the nature and magnitude of forces and the related binding energy landscape. For example, by attaching one of the interacting proteins to the AFM tip and the other protein to the sample surface, the molecular binding forces can be quantified from the positive binding/ rupture events [18].

In the present work, a protein immobilization protocol is used for the controlled and oriented immobilization of $\mathrm{Ca}^{2+} / \mathrm{CaM}$. AFM was utilized to evaluate this procedure and investigate the interaction between the immobilized $\mathrm{Ca}^{2+} / \mathrm{CaM}$ and the CaM KI binding domain. $\mathrm{Ca}^{2+} / \mathrm{CaM}$ and $\mathrm{CaM}$ KI binding domain were concerned as subjects in the case of this study because their interactions in bulk solution have been fully studied by circular dichroism (CD), nuclear magnetic resonance (NMR), and electron paramagnetic resonance (EPR) [19]. The structure of CaM KI and the substrate sequence recognition motif for CaM KI are therefore clear.

\section{Experimental}

\section{Chemicals and materials}

Chemicals for surface preparation

Octadecyltrichlorosilane (OTS, 97\%) and (11-mercaptoundecyl)trimethoxysilane (MUTMS, 95\%) were purchased from Gelest. Toluene (HPLC grade) was purchased from Fisher Scientific. Ultraflat silicon (100) wafers (N-type) were purchased from Sigma-Aldrich Corporation. Sulfuric acid and hydrogen peroxide were purchased from Sigma-Aldrich Corporation.

\section{Materials for CaM expression, purification, and reaction}

Luria-Bertani (LB) broth, used to grow the cell culture, and Tris(2-carboxyethyl) phosphine hydrochloride (TCEP) disulfide reducing agent were purchased from Sigma-Aldrich Corporation. Calcium chloride $\left(\mathrm{CaCl}_{2}\right)$ was purchased from Flinn Scientific. CaM was purified using chitin beads from New England Biolabs. 2-anilinonaphthalene-6-sulfonic acid (ANS) used for fluorescence experiment and SDS-PAGE were obtained from Invitrogen Corporation. Calmodulin-dependent protein kinase I (299-320) binding domain, which is a putative CaM-binding region, was obtained from AnaSpec. All the solution was prepared with water from a Millipore Direct-Q UV water purification system.

\section{Protein expression and purification}

Purification and expression of genetically engineered $\mathrm{CaM}$ with cysteine on $\mathrm{N}$-terminus is based on instructional manual prepared by New England Biolabs [20]. In order to prevent dimer formation, TCEP was applied in protein solution. SDS-PAGE was used to confirm the CaM purity (see Additional file 1 ).

In our experiment, we used 2,6-anilinonaphthalene sulfonate (ANS) fluorescent probe to test the bio-activity of the purified solution-state $\mathrm{Ca}^{2+} / \mathrm{CaM}$. It is well established that solvent-exposed hydrophobic surfaces are formed upon $\mathrm{Ca}^{2+}$ binding to $\mathrm{CaM}$, and ANS binds to the hydrophobic parts of proteins through polar interactions and can be monitored by the increase in fluorescence emission intensity, which demonstrates the activity of $\mathrm{Ca}^{2+} / \mathrm{CaM}$ indirectly [21]. When EDTA is added to the solution, $\mathrm{Ca}^{2+}$ is removed from $\mathrm{Ca}^{2+} / \mathrm{CaM}$, and the hydrophobic binding pocket disappears. This conformational change causes the release of bound ANS from CaM to the aqueous solutions, leading to a decrease in fluorescence intensity. Therefore, by monitoring the fluorescence intensity variation we can confirm the conformational change in $\mathrm{CaM}$, which is an indication of CaM viability [22].

During the experiment, the protein was labeled with a 1:1 ratio of ANS overnight at room temperature followed by dialysis against the same buffer. $1 \mu \mathrm{L}$ increments 
$0.5 \mathrm{mmol} \mathrm{L}{ }^{-1}$ EDTA was added into the $400 \mu \mathrm{L} \mathrm{CaM}$ solution each time. The solution was excited at $310 \mathrm{~nm}$, and emission spectra in the range from 400 to $500 \mathrm{~nm}$ were obtained with a Perkin Elmer LS-55 fluorescence spectrometer. Figure 1 shows a sigmoidal shape of the binding curve which was observed by adding EDTA solution into CaM solution accumulatively. As expected, the increase of EDTA amount led to a decrease in fluorescence signal intensity due to the release of ANS caused by EDTA-induced CaM conformational change. The fluorescence intensity change indicates that our purified $\mathrm{CaM}$ was capable of changing its conformation properly in the solution state.

\section{Surface fabrication}

The fabrication and characterization of the chemical pattern were performed with an Agilent PicoPlus 3000 AFM in an environmental chamber. AFM can provide atomiclevel resolution in $z$ axis. The Si (100) wafer was cut into $1 \mathrm{~cm} \times 1 \mathrm{~cm}$ pieces. Then, the wafer was boiled in the

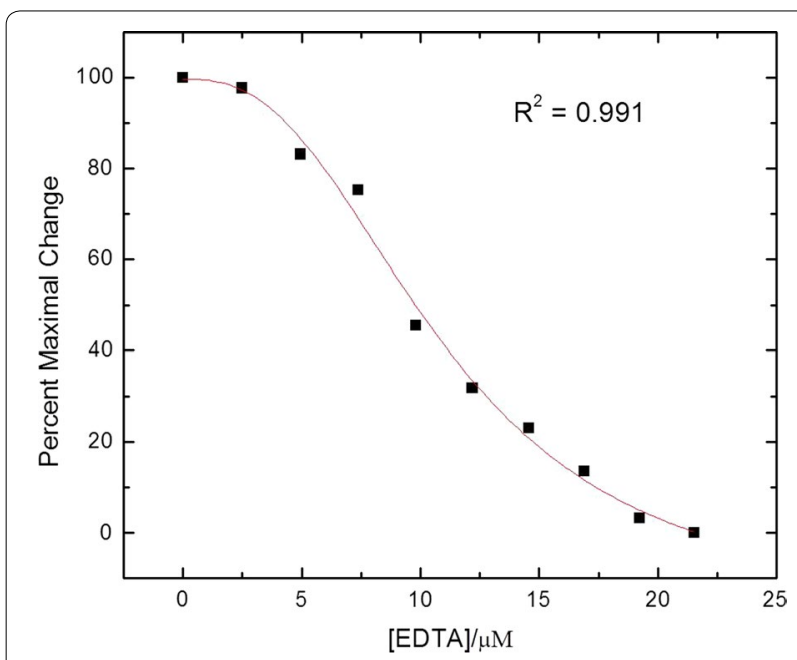

Fig. 1 EDTA titrations of ANS labeled CaM monitored by ANS fluorescence emission measurement. For purpose of comparison, all the fluorescence intensities were normalized to their respective 100\% change. Sigmoidal fitting along with coefficient of determination $\left(R^{2}\right)$ were also demonstrated in Fig. 1 piranha solution (two parts of $98 \%$ sulfuric acid and one part of $30 \%$ hydrogen peroxide) at $170{ }^{\circ} \mathrm{C}$ for $30 \mathrm{~min}$. At high temperature, the $\mathrm{H}_{2} \mathrm{O}_{2}$ was decomposed; $\mathrm{O}$. and $\mathrm{OH}$. were generated to remove all organic contaminants and also help to grow a thin oxide layer of silanol $(\mathrm{Si}-\mathrm{OH})$ on the surface. After that, the wafer was dipped into $5 \mathrm{mmol} \mathrm{L}{ }^{-1}$ OTS toluene solution for a pinholefree OTS-coated wafer fabrication, which was capable of being used for the follow-up experiment [23-26].

The experimental scheme was shown in Fig. 2. Chemical patterns on the OTS coated Si wafer were fabricated using local oxidation lithography first (Fig. 2a). With the help of the chemical patterns, we are able to modify surface with defined chemistry and create topography with references in positions and height. A detailed description of the OTS partially degraded pattern (OTSpd) fabrication has been demonstrated in Additional file 1, and an OTSpd pattern fabrication set-up was demonstrated in Additional file 1: Figure S2 [27].

From the AFM topography histogram (Additional file 1: Figure S3b), we can know the depth of the OTSpd pattern is $10.60 \pm 0.01 \AA$ lower than the OTS background. The depth of the OTSpd chemical pattern provides a height reference for calculating the thickness of other parallel layer on itself. Although some studies applied AFM cross-section profile to analyze the height of object [28-30], it is believed that AFM topography histogram can better represent the average height change of pattern areas in the present work due to the protein film, which is immobilized on the chemical patterns, exhibiting an "unflat" surface. Histograms of the corresponding heights were fitted to two Gaussian functions by using MicroCal Origin software in order to enable a quantitative comparison. The distance between these two peaks is the height of the disk pattern [31].

After the OTSpd patterns were fabricated, the substrate was rinsed in 10\% hydrochloric acid for $10 \mathrm{~min}$ and cleaned with the super-critical carbon dioxide snow jet cleaner from Applied Surface Technologies. The possible electrostatic charges and contaminates were completely removed as a result of above procedures. Then,

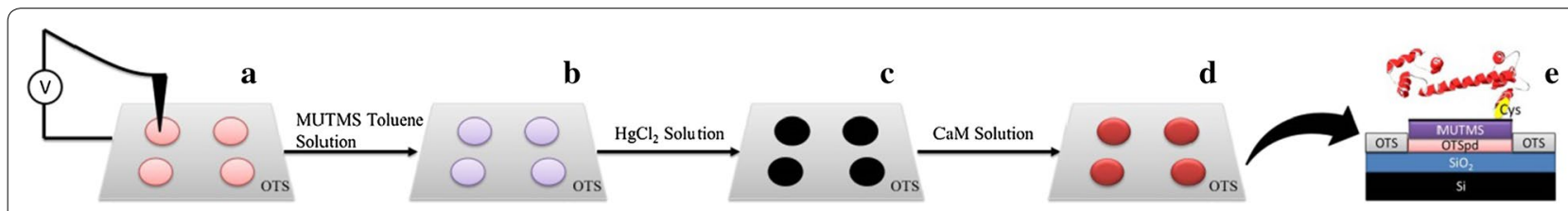

Fig. 2 The Scheme for CaM patterns fabrication. a The OTSpd disk patterns were fabricated by local oxidation lithography. b MUTMS was crosslinked onto the OTSpd patterns, converting the OTSpd patterns into thiol-terminated surfaces. c Substrate was then incubated into $\mathrm{HgCl}_{2}$ solution to form $\mathrm{Hg}$-SH coupling. $\mathbf{d}$ Cysteine-mutated CaM was immobilized on the chemical patterns via cysteine-Hg-SH coupling. e Structural model of substrate corresponding to part (d) 
the pattern was soaked in a $10 \mathrm{mmol} \mathrm{L}^{-1}$ MUTMS toluene solution overnight to convert the carboxylic acidterminated OTSpd surface pattern to a thiol-terminated surface pattern (Fig. 2b). The structure and formation of MUTMS layer on OTSpd pattern is illustrated in Fig. 3. MUTMS molecules react with the trace amount of water in the solution, forming silanols in the first step. Then the silanols cross-linked and selectively anchored on the hydrophilic OTSpd surface. The pattern in Additional file 1: Figure S4 is a representative MUTMS silane monolayer self-assembled on top of the OTSpd pattern. From AFM characterization, the height of the MUTMS pattern over the OTS background is $10.62 \pm 0.02 \AA$.

Then, the sample with MUTMS patterns was incubated into $10 \mathrm{mmol} \mathrm{L}^{-1} \mathrm{HgCl}_{2}$ solution for half an hour to form $\mathrm{SH}-\mathrm{Hg}$ coupling, as shown in Fig. 3c, which will be used to immobilize cysteine-mutated CaM. $5 \mu \mathrm{g} \mathrm{mL}^{-1}$ $\mathrm{CaM}$ with buffer solution $\left(25 \mathrm{mmol} \mathrm{L} \mathrm{L}^{-1}\right.$ Tris- $\mathrm{HCl}$, $1 \mathrm{mmol} \mathrm{L}^{-1} \mathrm{CaCl}_{2}, \mathrm{pH}$ 8.0) was deposited onto the pattern area for one hour in refrigerator at $4{ }^{\circ} \mathrm{C}$ (Fig. 3d) [32]. Then the sample surface was wiped with a piece of ChemWipe paper, in a typical force of $1 \mathrm{~N}$ [33], to remove the nonspecifically adsorbed protein on the OTS background, while those specifically bind to substrate surface remained.

\section{Surface characterization}

Because AFM imaging in liquid environment provides a less accurate measurement [34], and it is difficult to interpret the AFM phase image taken in liquid environment [35]; CaM patterns were imaged at $75 \%$ relative humidity environment $\left(\right.$ at $25{ }^{\circ} \mathrm{C}$ ) in air in ac mode with MikroMasch NSC-14 tips. The imaging set point was maintained at $99 \%$ of the tip free oscillation amplitude so that the tip tapped the CaM immobilized surface under a minimal force. Because the tip touched the protein surface in the humid environment, a possible electrostatic charge from the sample was dissipated after the tip touched the sample. Hence, the height measurement was not affected by the protein's electrostatic charge. All AFM images were processed using WSxM [36].

\section{Results and discussion}

The MUTMS modified surface was used to immobilize cysteine-mutated $\mathrm{CaM}$ through cysteine- $\mathrm{Hg}-\mathrm{SH}$ coupling. Figure 4a demonstrates a protein pattern in which protein film was made only partially covered the MUTMS disk intentionally. Therefore, Fig. 4a includes the surface features of OTS, MUTMS, and protein. To create protein molecules partially covered patterns, we swabbed the surface with a piece of ChemWipe paper in a force greater than $5 \mathrm{~N}$. Under such condition, ChemWipe paper can remove protein molecules that are nonspecifically adsorbed on the OTS background, and also scratch off some protein molecules which are specifically immobilized on the chemical template. AFM topography characterizations show that after protein immobilization procedure, the height of the patterns changed to

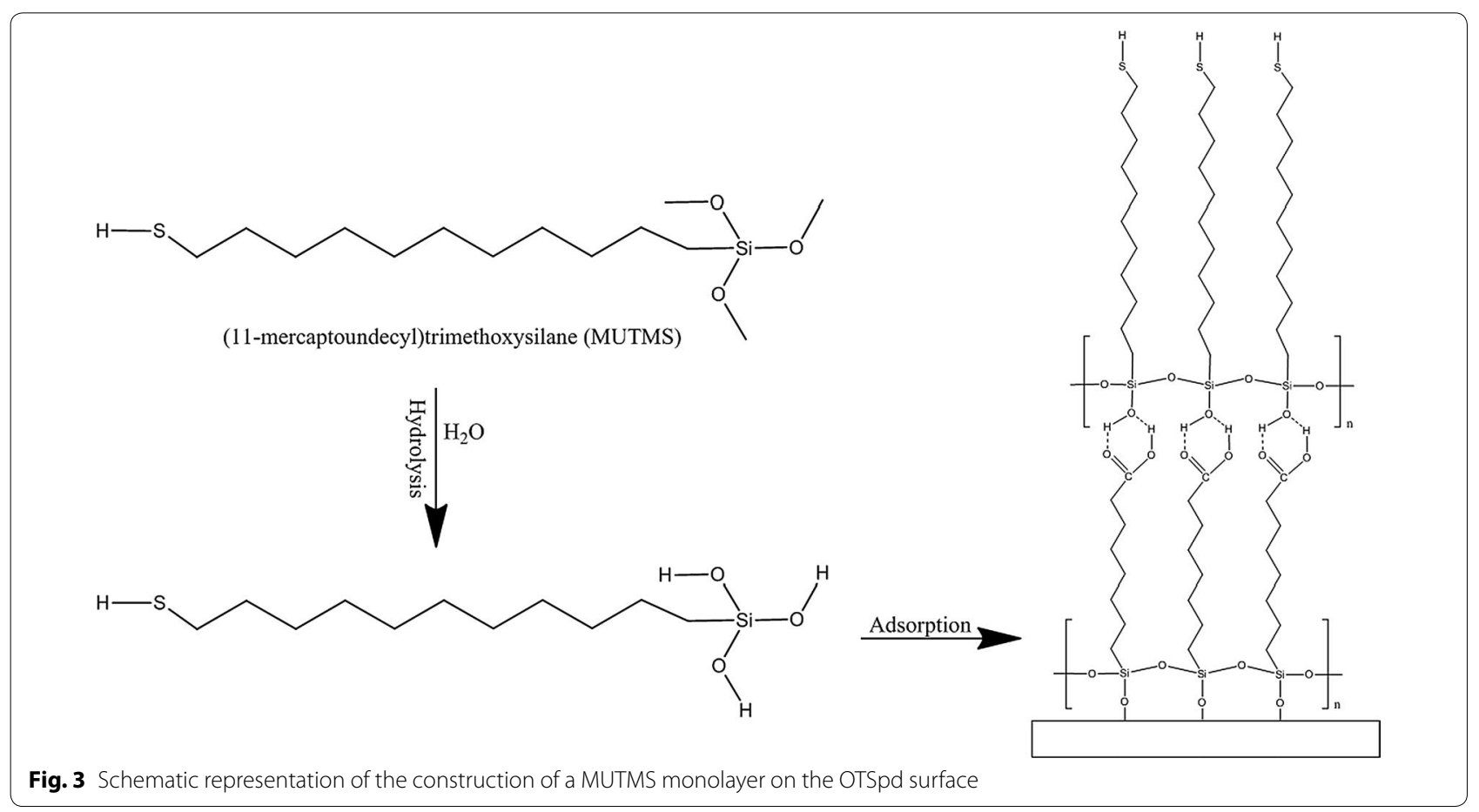



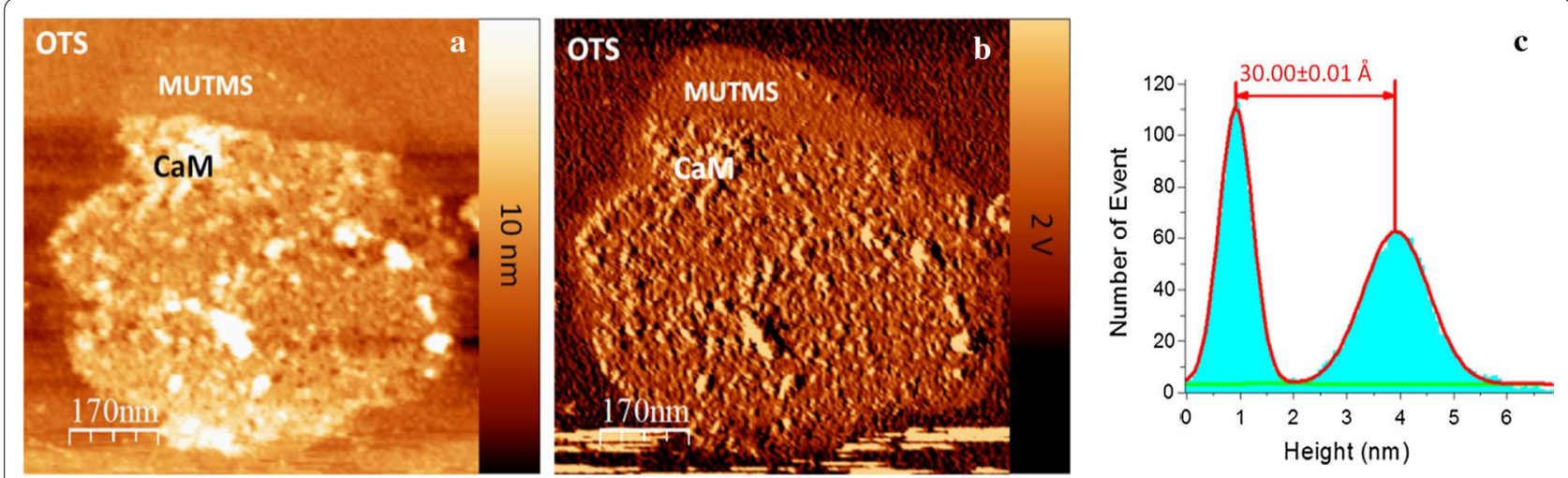

Fig. 4 A partially covered CaM layer on the MUTMS pattern. a Ac mode topography image. b Corresponding phase image. $\mathbf{c}$ Histogram corresponding to protein fully covered area in (a). The distance between the two peaks in the histogram specifies the height of the CaM pattern over OTS background in (a)

$3.00 \pm 0.01 \mathrm{~nm}$ above the OTS background (Fig. 4a). In the corresponding phase image (Fig. 4b), the phase signal of the MUTMS pattern area is $282.18 \pm 68.34 \mathrm{mV}$, which is different from the phase signal of protein pattern area $122.67 \pm 88.2 \mathrm{mV}$, indicating they have different surface identities [37]. From both AFM topography and phase signal, we can conclude that CaM was immobilized on the MUTMS chemical pattern.

CaM KI binding domain is an amino acids 299 to 320 fragment of the CaM KI, which can independently bind $\mathrm{CaM}$ and be utilized for CaM interaction studies [38]. $\mathrm{Ca}^{2+} / \mathrm{CaM}$ can capture this fragment by wrapping tightly around it, inducing a calmodulin conformational change. In the experiment, the immobilized CaM was soaked for $10 \mathrm{~min}$ in a $1 \mathrm{~g} \mathrm{~mL}^{-1} \mathrm{CaM} \mathrm{KI}$ binding domain solution at $4{ }^{\circ} \mathrm{C}$. Figure $5 \mathrm{a}, \mathrm{b}$ show the CaM pattern, after treatment with CaM KI binding domain solution for $10 \mathrm{~min}$ and then rinsed with copious amounts of buffer solution, in topography and phase channels, respectively. The MUTMS/OTS border, protein/MUTMS border, and protein/OTS border are recognizable in the phase image indicating the surface was not covered by CaM KI binding domain. The clean, protein uncovered MUTMS surface (Fig. 5a) indicates the non-specifically adsorbed protein molecules were removed. AFM tip was manipulated to scan on the surface of protein pattern multiple times. The height of the protein pattern maintained the same after the AFM tip scanning, indicating that the interaction between CaM KI binding domain and the immobilized $\mathrm{CaM}$ is specific. Otherwise, the non-specifically adsorbed CaM KI binding domain could be wiped off by AMF tip during its scanning on surface, and the height of the protein pattern should decrease correspondingly. The results from AFM histogram (Fig. 5c)
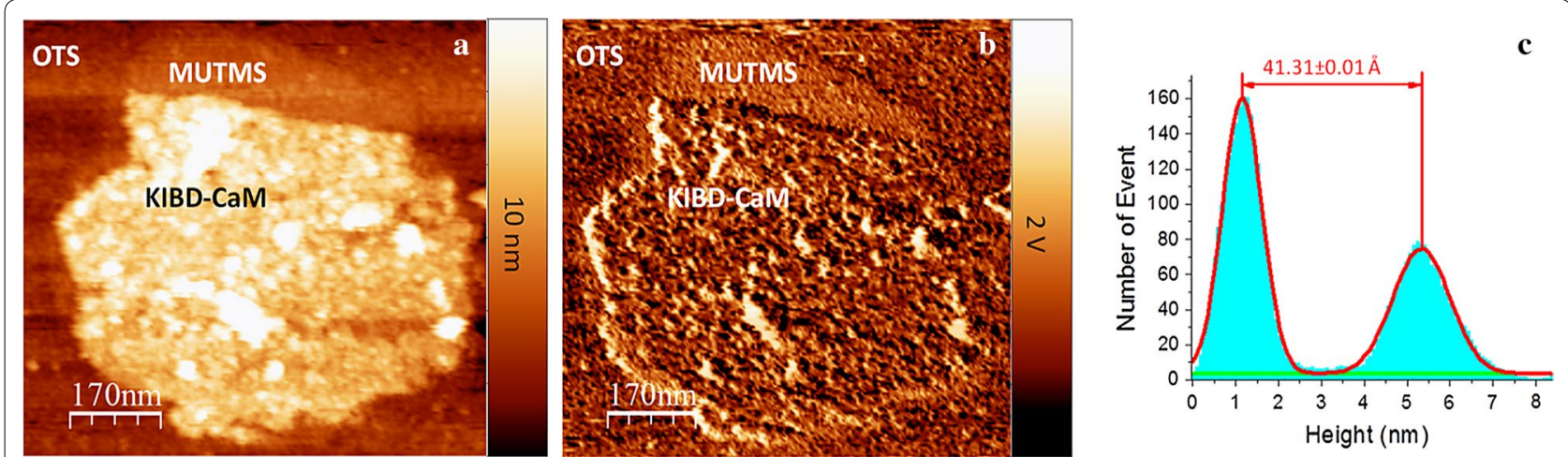

Fig. 5 Sample in Fig. 4 was incubated in CaM KI binding domain solution for 10 min. a AFM ac mode topography image. b Corresponding phase image. c Histogram corresponding to protein fully covered area in (a). The distance between the two peaks in the histogram specifies the height of the KIBD-CaM pattern over OTS background in (a) 
reveals that the CaM KI binding domain causes the height of the CaM layer to increase $11.31 \pm 0.10 \AA$, which indicates that the immobilized CaM still remained activity to bind its target protein.

In Fig. 6, we plot the height cross-sectional profiles corresponding to the same location of MUTMS pattern before (black line) and after (red line) the CaM KI binding domain solution incubation. Cross-sectional profiles (Fig. 6c) show that the height of MUTMS above OTS background remains the same after the CaM KI binding domain solution incubation, indicating no CaM KI binding domain bound on the MUTMS surface.

MUTMS, CaM, and CaM KI binding domain-bound CaM (KIBD-CaM) patterns were also characterized for different samples to obtain better statistical results. The final results are summarized in Table 1.
Table 1 Height of the surface patterns

\begin{tabular}{lll}
\hline & Apparent height above OTS $(\mathbf{n m})$ & $\mathbf{N}$ \\
\hline MUTMS & $1.08 \pm 0.18$ & 30 \\
CaM & $2.95 \pm 0.06$ & 18 \\
KIBD-CaM & $4.20 \pm 0.09$ & 15 \\
\hline
\end{tabular}

\section{Conclusions}

Our results show that the immobilized CaM retains its activity to interact with its target protein. Upon conformation change to KIBD-CaM, the apparent height of the CaM molecules increased. Our results demonstrate the feasibility of employing AFM to probe and understand the protein-protein interaction. We expect to find wide applications of this present methodology in
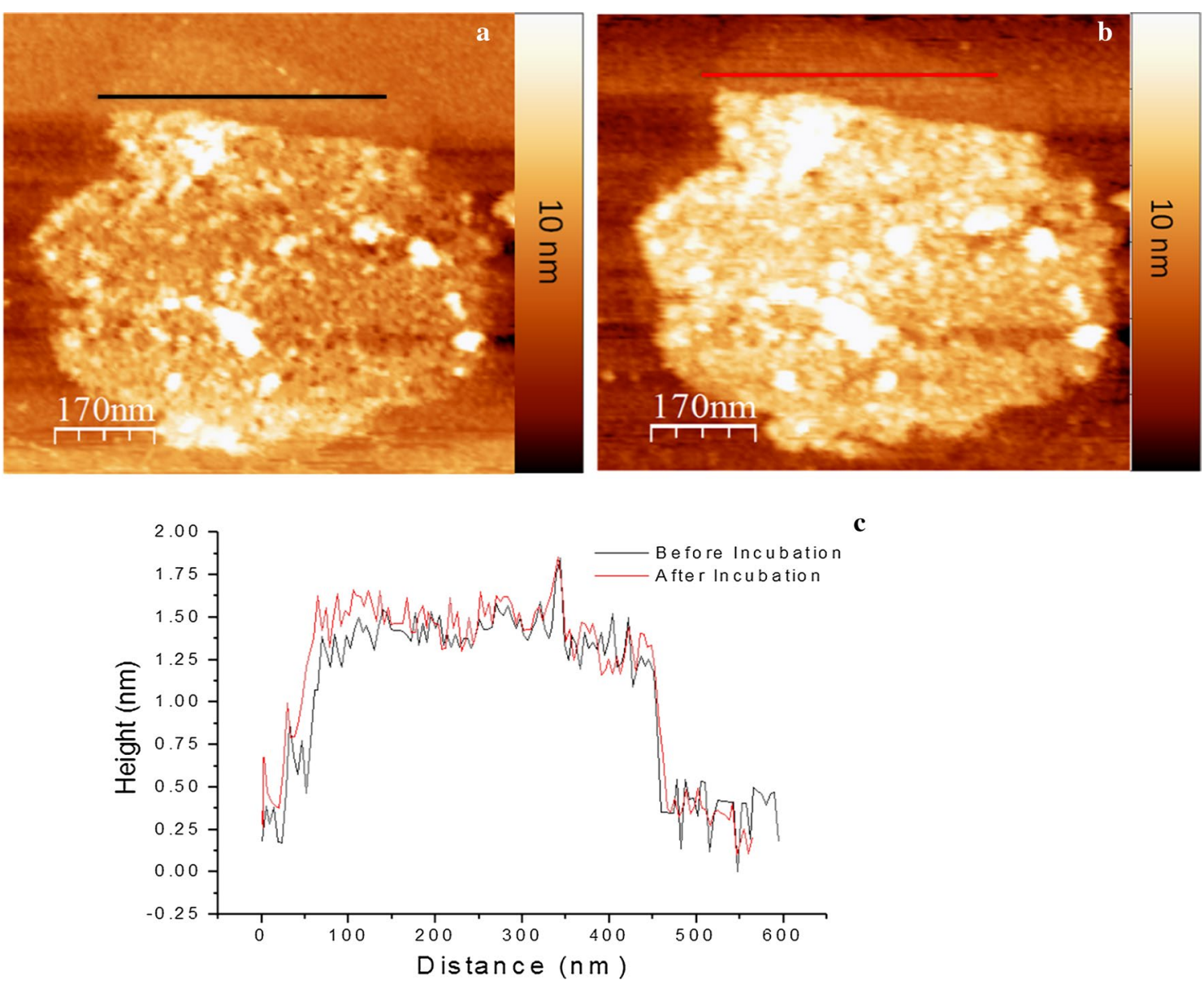

Fig. 6 CaM Kl binding domain can bind immobilized CaM (a) inducing a conformational change (b). The height cross-sectional profiles of the same position on MUTMS patterned area in $(\mathbf{a})$ and $(\mathbf{b})$ were plotted in (c) 
surface-based protein-protein interactions biosensors, bioelectronics or drug screening.

\section{Additional file}

Additional file 1. Supporting information.

\begin{abstract}
Abbreviations
CaM: calmodulin; AFM: atomic force microscopy; OTS: octadecyltrichlorosilane; OTSpd: OTS partially degraded; MUTMS: (11-mercaptoundecyl) trimethoxysilane; LB: Luria-Bertani; TCEP: Tris(2-carboxyethyl)phosphine hydrochloride; ANS: 2-anilinonaphthalene-6-sulfonic acid; CaM KI: CaM kinase I/CaM-dependent protein kinase I; PSD: post-synaptic density; AMPA receptors: phosphrylates á-amino-3-hydroxy-5-methyl-4-isoxazolepropionic acid receptors; KIBD-CaM: CaM KI binding domain-bound CaM.
\end{abstract}

\section{Authors' contributions}

All authors carried out the experiments and the writing of the manuscript. Both authors read and approved the final manuscript.

\section{Author details}

${ }^{1}$ College of Biotechnology, Southwest University, Chongqing 400715, China.

${ }^{2}$ Key Laboratory of Mariculture and Enhancement of Zhejiang Province, Marine Fishery Institute of Zhejiang Province, Zhoushan 316021, China.

\section{Acknowledgements}

Xiaoning Zhang gratefully acknowledges the financial support from the National Science Foundation (HRD-1505197) and a Start-up Fund of Southwest University grant (SWU117036). Hongmei Hu is grateful for financial support from Science and Technology Project of Zhejiang Province (2017F50021), Talent Project of Zhejiang Association for Science and Technology (2017YCGC013), Science and Technology Project of Zhoushan City (2016C31055)

\section{Competing interests}

The authors declare that they have no competing interests.

Ethics approval and consent to participate

Not applicable.

\section{Publisher's Note}

Springer Nature remains neutral with regard to jurisdictional claims in published maps and institutional affiliations.

Received: 23 August 2017 Accepted: 30 November 2017

Published online: 06 December 2017

\section{References}

1. Cahill DJ (2001) Protein and antibody arrays and their medical applications. J Immunol Methods 250:81-91

2. Zhu H, Snyder M (2003) Protein chip technology. Curr Opin Chem Biol 7:55-63

3. Blawas AS, Reichert WM (1998) Protein patterning. Biomaterials 19:595-609

4. Lee Y, Lee EK, Cho YW, Matsui T, Kang IC, Kim TS et al (2003) ProteoChip: a highly sensitive protein microarray prepared by a novel method of protein, immobilization for application of protein-protein interaction studies. Proteomics 3:2289-2304

5. Vogel HJ (2002) Calcium-binding protein protocols. Humana Press, Totowa

6. Chin D, Means AR (2000) Calmodulin: a prototypical calcium sensor. Trends Cell Biol 10:322-328
7. Swindells MB, Ikura M (1996) Pre-formation of the semi-open conformation by the apo-calmodulin C-terminal domain and implications for binding IQ-motifs. Nat Struc Biol 3:501-504

8. Osawa M, Swindells MB, Tanikawa J, Tanaka T, Mase T, Furuya T et al (1998) Solution structure of calmodulin-W-7 complex: the basis of diversity in molecular recognition. J Mol Biol 276:165-176

9. Zuhlke RD, Pitt GS, Deisseroth K, Tsien RW, Reuter H (1999) Calmodulin supports both inactivation and facilitation of L-type calcium channels. Nature 399:159-162

10. Dzhura I, Wu YJ, Colbran RJ, Balser JR, Anderson ME (2000) Calmodulin kinase determines calcium-dependent facilitation of L-type calcium channels. Nat Cell Biol 2:173-177

11. Pawson T, Gish GD, Nash P (2001) SH2 domains, interaction modules and cellular wiring. Trends Cell Biol 11:504-511

12. Songyang Z, Cantley LC (1995) Recognition and specificity in protein tyrosine kinase-mediated signalling. Trends Biochem Sci 20:470-475

13. Gijsbers A, Nishigaki T, Sánchez-Puig N (2016) Fluorescence anisotropy as a tool to study protein-protein interactions. J Vis Exp Jove 2016(116):e54640

14. Benz C, Retzbach H, Nagl S, Belder D (2013) Protein-protein interaction analysis in single microfluidic droplets using FRET and fluorescence lifetime detection. Lab Chip 13:2808-2814

15. Kameshita I, Ishida A, Fujisawa H (1998) Analysis of protein-protein interaction by two-dimensional affinity electrophoresis. Anal Biochem 262:90-92

16. Xu M, Liu C, Zhou M, Li Q, Wang R, Kang J (2016) Screening of small-molecule inhibitors of protein-protein interaction with capillary electrophoresis frontal analysis. Anal Chem 88:8050-8057

17. Okhrimenko O, Jelesarov I (2008) A survey of the year 2006 literature on applications of isothermal titration calorimetry. J Mol Recognit 21:289-311

18. Marcuello C, Miguel RD, Gómezmoreno C, Martínezjúlvez M, Lostao A (2012) An efficient method for enzyme immobilization evidenced by atomic force microscopy. Protein Eng Des Sel Peds 25:715-723

19. Yuan T, Gomes AV, Barnes JA, Hunter HN, Vogel HJ (2004) Spectroscopic characterization of the calmodulin-binding and autoinhibitory domains of calcium/calmodulin-dependent protein kinase I. Arch Biochem Biophys 421:192-206

20. Perrin FX, Nguyen TDH, Nguyen DL (2015) Formation, structure and antibacterial activities of silazane networks grafted with poly(ethylene glycol) branches. Prog Org Coat 88:92-105

21. Means AR, Dedman JR (1980) Calmodulin—an intracellular calcium receptor. Nature 285:73-77

22. Crivici A, Ikura M (1995) Molecular and structural basis of target recognition by calmodulin. Annu Rev Biophys Biomol Struct 24:85-116

23. Maoz R, Cohen SR, Sagiv J (1999) Nanoelectrochemical patterning of monolayer surfaces: toward spatially defined self-assembly of nanostructures. Adv Mater 11:55-61

24. Maoz R, Frydman E, Cohen SR, Sagiv J (2000) "Constructive nanolithography": inert monolayers as patternable templates for in situ nanofabrication of metal-semiconductor-organic surface structures: a generic approach. Adv Mater 12:725-731

25. Hoeppener S, Maoz R, Cohen SR, Chi LF, Fuchs H, Sagiv J (2002) Metal nanoparticles, nanowires, and contact electrodes self-assembled on patterned monolayer templates: a bottom-up chemical approach. Adv Mater 14:1036-1041

26. Liu ST, Maoz R, Schmid G, Sagiv J (2002) Template guided self-assembly of (Au55) clusters on nanolithographically defined monolayer patterns. Nano Lett 2:1055-1060

27. Cai YG, Ocko BM (2005) Electro pen nanolithography. J Am Chem Soc 127:16287-16291

28. Yun X, Tang M, Yang Z, Wilksch JJ, Xiu P, Gao H et al (2017) Interrogation of drug effects on HeLa cells by exploiting new AFM mechanical biomarkers. Rsc Adv 7:43764-43771

29. Li N, Jang H, Yuan M, Li W, Yun X, Lee J et al (2017) Graphite-templated amyloid nanostructures formed by a potential pentapeptide inhibitor for alzheimer's disease: a combined study of real-time atomic force microscopy and molecular dynamics simulations. Langmuir Acs J Surf Coll 33:6647-6656 
30. Feng Z, Ping Z, Hou J, Yun X, Li W, Du Q et al (2015) Large scale anomalous patterns of muscovite mica discovered by atomic force microscopy. Acs Appl Mater Interfaces 7:8699-8705

31. Eaton P, West P (2010) Atomic Force Microscopy. OUP, Oxford

32. Trajkovic S, Zhang XN, Dauner S, Cai YG (2011) Atomic force microscopy study of the conformational change in immobilized calmodulin. Langmuir 27:10793-10799

33. Gao P, Cai YG (2009) A method for fabricating protein patterns on the octadecyltrichlorosialne(OTS) surface through paper swabbing. Ultramicroscopy 109:1023-1028

34. Mikromasch "Life Science". http://www.spmtips.com/how-to-chooseafm-probes-by-applications-life-science.html. Accessed 17 Dec 2015
35. Chen CH, Clegg DO, Hansma HG (1998) Structures and dynamic motion of laminin-1 as observed by atomic force microscopy. Biochemistry 37:8262-8267

36. Horcas I, Fernandez R, Gomez-Rodriguez JM, Colchero J, Gomez-Herrero J, Baro AM (2007) WSXM: a software for scanning probe microscopy and a tool for nanotechnology. Rev Sci Instrum 78:013705

37. Zhang X, Cai Y (2012) Octadecyltrichlorosilane (OTS)-coated ionic liquid drops: micro-reactors for homogenous catalytic reactions at designated interfaces. Beil J Nanotechnol 3:33-39

38. Gomes AV, Barnes JA, Vogel HJ (2000) Spectroscopic characterization of the interaction between calmodulin-dependent protein kinase i and calmodulin. Arch Biochem Biophys 379:28-36

\section{Submit your manuscript to a SpringerOpen ${ }^{\circ}$ journal and benefit from:}

- Convenient online submission

- Rigorous peer review

- Open access: articles freely available online

- High visibility within the field

- Retaining the copyright to your article

Submit your next manuscript at $\boldsymbol{\nabla}$ springeropen.com 